\title{
Bladder dysfunction in diabetes mellitus
}

\author{
Saeid Golbidi and Ismail Laher*
}

Department of Pharmacology and Therapeutics, Faculty of Medicine, University of British Columbia, Vancouver, BC, Canada

\section{Edited by:}

Eliot Ohlstein, Drexel Med School, USA

Reviewed by:

Eliot Ohlstein, Drexel Med School, USA

Donna Jayne Sellers, Bond University,

Australia

\section{*Correspondence:}

Ismail Laher, Department of

Pharmacology and Therapeutics,

Faculty of Medicine, University of

British Columbia, Vancouver, BC,

Canada V6T 1 Z3.

e-mail: ilaher@interchange.ubc.ca
Diabetic cystopathy is a well-recognized complication of diabetes mellitus, which usually develops in middle-aged or elderly patients with long-standing and poorly controlled disease. It may have broad spectrum clinical presentations. Patients may be asymptomatic, or have a wide variety of voiding complaints from overactive bladder and urge incontinence to decreased bladder sensation and overflow incontinence. This review focuses on pathophysiological mechanisms responsible for urologic complications of diabetes and emphasizing on recent developments in our understanding of this condition. We also tried to shed some light on therapeutic modalities like behavioral, pharmacological, and surgical approaches.

Keywords: diabetes, neurogenic bladder, cystopathy, incontinence

\section{BACKGROUND}

Micturition is a highly coordinated process that starts with sensing bladder filling, transferring data to the central nervous system processing center and efferent pathways resulting in the voiding response. Increasing the volume of the urinary bladder provokes afferent signals to the central nervous system. The molecular basis of distention sensing has not been fully clarified, but may involve the urothelium as a major factor during this process. The urothelium represents the layer of epithelial cells lining the urinary tract between the renal pelvis and the urinary bladder. For many years, it was considered as a passive barrier for the passage of ions and solutes, but currently is known to possess a number of novel features that allow it to respond to various physical and chemical stimuli, resulting in the release of various substances from the urothelial cells: these include ATP, nitric oxide (NO), substance P, acetylcholine, adenosine, antiproliferative factor, cytokines, various trophic factors, and prostanoids (Birder and de Groat, 2007).

During bladder filling at low volumes, low frequency impulses activate afferent nerves to signal the pontine storage and micturition centers, and stimulate sympathetic outflow via hypogastric and pudendal nerves. Released norepinephrine induces detrusor relaxation and enhances bladder compliance, which is mediated largely through $\beta_{3}$-adrenergic receptors, while bladder outlet resistance is enhanced by activation of $\alpha_{1}$-adrenergic receptors in the bladder neck, urethra and prostate (Michel and Vrydag, 2006). The somatic nerves also participate in the process of increasing bladder outlet resistance by releasing acetylcholine. Increasing urine volume will increase the frequency of afferent impulses, which in turn will shift efferent signaling from the pontine storage to the micturition center. This activates parasympathetic and inhibit sympathetic outflow. The resultant acetylcholine stimulates detrusor muscle through mainly $\mathrm{M}_{3}$ muscarinic receptor subtypes (and also $\mathrm{M}_{2}$ receptors during pathophysiological situations) (Abrams et al., 2006; Hegde, 2006).

Voiding dysfunction manifests in various forms including urinary frequency, nocturia, urinary retention, and urinary incontinence. The two most frequent causes of incontinence are (a) excessive pressure development by the bladder (urgency urinary incontinency) and (b) reduced bladder outlet resistance (stress urinary incontinence). Mixed forms of these two forms are frequently encountered in clinical practice (Michel et al., 2004). An overactive bladder originates from involuntary detrusor contractions during the filling phase of the micturition cycle; it can occur with or without incontinence, and frequently manifests as urinary frequency and nocturia.

\section{PATHOPHYSIOLOGY OF BLADDER DYSFUNCTION IN DIABETES}

Diabetic bladder dysfunction refers to a group of bladder symptoms occurring in patients with diabetes mellitus. Diabetic bladder dysfunction presents in a spectrum of clinical symptoms representing a number of disorders ranging from bladder overactivity to impaired bladder contractility. Its prevalence has been estimated as being between 25 and $87 \%$ (Frimodt-Møller, 1980). However, since diabetes tends to occur in the elderly population, concurrent factors such as benign prostatic hyperplasia, neurological disorders, and aging may also contribute to voiding dysfunction, and makes it difficult to assess the specific contribution of the diabetic state to voiding dysfunction in these patients. Diabetic cystopathy was used by Frimodt Moller in 1976 and refers to lower urinary symptoms due to diabetic neuropathy (Hill et al., 2008). Diabetic cystopathy is characterized by increased post voiding residual volumes and enhanced bladder capacity that is accompanied by decreased bladder sensation and contraction secondary to damage of visceral afferent fibers in the bladder wall (Kebapci et al., 2007). This insidious process causes gradual changes in patient's voiding patterns, with a reduced desire to void, which usually occurs at a stored urine volume of $300-400 \mathrm{ml}$ in healthy subjects (Smith, 2006). These patients commonly experience difficulty in initiating and maintaining micturition. Therefore, voiding reflexes appear sluggish and an asymptomatic increase in bladder capacity and urinary retention occurs. On the other hand, diabetic bladder dysfunction can also present as an overactive bladder syndrome usually described as urgency, with or without incontinence, usually with urinary frequency and nocturia. Indeed bladder hypersensitivity and hypercontractility is much more common than bladder 
hypo-contractility. More than half $(-55 \%)$ of diabetic patients have detrusor hyperreflexia, while another $23 \%$ have reduced detrusor contractility and a further $10 \%$ demonstrate detrusor areflexia with the remaining 11\% showing indeterminate findings (Kaplan et al., 1995). Based on both animal studies and human findings, Daneshgari et al. (2009) presented the "temporal theory of diabetic bladder dysfunction" which proposes that hyperglycemia-induced polyuria plays a major pathophysiological role during the early stages of diabetes polyuria, causing compensatory bladder hypertrophy and associated myogenic and neurogenic alterations. This stage is compatible with findings of a hyperactive bladder during urodynamic evaluation when patients present with bladder storage concerns (urgency or urge incontinence). With time and accumulation of toxic metabolites, decompensation of bladder tissue and function ensues, resulting in the classical signs and symptoms of diabetic cystopathy (hypocontractile detrusor or atonic bladder) in patients with urinary voiding problems.

\section{PATHOGENESIS}

The pathogenesis of diabetes induced bladder dysfunction is multifactorial. Alterations in detrusor muscle physiology, neuronal impairment, and urothelial dysfunctions are considered as participating factors (Yoshimura et al., 2005).

\section{ROLE OF DETRUSOR MUSCLE}

Changes in the physiology of detrusor muscle are attributed to different mechanisms such as changes in intercellular connections and excitability, receptors density and distribution, alteration in intracellular signaling, and genetic changes (Yoshimura et al., 2005). However, there are several uncertainties and controversies related to the magnitude and the time course of these changes, and to our knowledge, nearly all of these conclusions are based on animal studies and with unknown relevance to human pathophysiology. The detrusor muscle shows an enhanced response to muscarinic agonists in diabetes. It may be due to an increased muscarinic receptor density (Saito et al., 1997) or increases in smooth muscle sensitivity to calcium (Waring and Wendt, 2000). The latter effect may explain the increases maximal responses to carbachol, potassium, and electrical field stimulation occurring in the diabetic bladder (Waring and Wendt, 2000). Tong et al. (1999) reported a $70 \%$ increase in the density of M2-receptors within 2 weeks of the induction of diabetes in rats. Likewise, Kubota et al. (2003) also measured enhanced $\beta 1$-receptor mediated relaxation in detrusor smooth muscle isolated from rats $8-10$ weeks after induction of type 1 diabetes with streptozotocin (STZ).

Glucosuria and osmotic diuresis both lead to increased bladder stretch, elevated intravesical pressure, leading to bladder hypertrophy, which upon decompensation can cause increased residual volume (Daneshgari et al., 2006). Additionally, bladder hypertrophy can also exacerbate oxidative stress (Satriano, 2007). The decompensated bladder shows altered contractile characteristics and altered expression of muscarinic receptor subtypes also changed composition of myosin II isoforms. In addition, the increased expression of Rho A and Rho kinase in the hypertrophied bladder is associated with reduced myosin phosphatase activity (Peters et al., 2006), perhaps accounting for the augmented and prolonged responses to a depolarizing stimulus by $\mathrm{KCl}$ in hypertrophied bladder, and perhaps also provide pharmacological strategy for the treatment of bladder dysfunction. However, it is important to consider that the studies of the effects of diabetes on detrusor contractility have yielded both increased (Tammela et al., 1994; Waring and Wendt, 2000) and decreased contractility (Changolkar et al., 2005).

While there are many studies on the effect of oxidative stress on diabetic neuropathy, retinopathy, nephropathy, and cardiovascular dysfunction, there are relatively few reports on the role of oxidative stress on diabetic bladder dysfunction. Beshay and Carrier (2004) evaluated the oxidative status of the bladder in STZ-induced diabetes in rats and concluded that the observed oxidative stress (reduction of catalase-like activity, increase in thiobarbituric acid reactive substance level and increases in the number of inducible NO synthase positive cells) was not mediated by diuresis. Changolkar et al. (2005) measured increased lipid peroxidation and over expression of aldose reductase in alloxan induced diabetic rabbits. In the hyperglycemic state, the hexokinase pathway (which converts glucose into glucose-6-phosphate) becomes saturated and the affinity of aldose reductase for glucose increases, causing an increased production and accumulation of sorbitol that is transformed to fructose by the action of sorbitol dehydrogenase. These reactions are accompanied by oxidation (and consumption) of NADPH to $\mathrm{NADP}+$, and reduction of NAD+ to NADH. NADPH and NAD+ are necessary cofactors in redox reactions and their intracellular reduction leads to decreased synthesis of glutathione and other putative antioxidants such as taurine with an increased production of reactive oxygen species. Sorbitol also glycates nitrogen atoms on proteins (such as collagen) and the products of these glycations are referred to advanced glycation end products (Forbes et al., 2008). Daneshgari et al. (2009) provided unpublished evidence suggesting increased aldose reduction expression in human bladder smooth muscle cells under hyperglycemic conditions. The activation of the aldose reductase pathway also contributes to the activation of protein kinase $\mathrm{C}$, a signal transduction protein that is altered in some tissues prone to diabetic complications (Changolkar et al., 2005). Administration of ONO-2235, an aldose reductase inhibitor, to STZ-induced diabetic rats caused (a) improved cystometric parameters such as voiding volumes, voiding fraction, and residual volumes and (b) restored the decreased genetic expression of bladder nerve growth factor and neurotrophin receptor $\mathrm{p} 75^{\mathrm{NTR}}$, suggesting a role for the polyol pathway in the genetic down regulation of nerve growth factor and p $75^{\mathrm{NTR}}$ during cystopathy (Tong and Cheng, 2007). The p $75^{\mathrm{NTR}}$ protein is one of two classes of cell surface receptors for nerve growth factor that is expressed in sensory neurons. These findings are relevant as p75 positive nerve fibers have been identified in both human and rat bladder (Wakabayashi et al., 1995, 1996).

\section{ROLE OF NEURONAL DAMAGE}

Hyperglycemia can exert its toxic effects through neuronal damage; included in the possible mechanism for this is activation of the polyol pathway (which results in accumulation of sorbitol and fructose), increases the production of free radicals, activates protein kinase $\mathrm{C}$, and enhances the formation of advanced glycated end products (Fedele, 2005). These metabolic derangements lead to axonal degeneration and impairment of nerve conduction, which later on manifest itself as bladder hyposensation. A 
decrease in acetylcholinesterase activity in bladder biopsies of diabetic patients may be due to axonal degeneration and importantly, Schwann cell proliferation occurs in an attempt to cause a regenerative rescue after demyelination or axonal degeneration (Van Poppel et al., 1998).

The decreased synthesis of nerve growth factor in the bladder or the defective transport of nerve growth factor to the lumbosacral dorsal root ganglia is associated with diabetic neuropathy and bladder dysfunction (Brown et al., 2005). Nerve growth factor, a member of the neurotrophin factor family, is necessary for maintaining the normal function of mature sensory and sympathetic neurons in addition to its ability to promote survival of the neurons during development (Thoenen and Barde, 1980; Levi-Montalcini, 1987). Recent data also suggests a role for nerve growth factor in the processes of inflammation and pain (Steers and Tuttle, 2006). Diminished retrograde axonal transport of nerve growth factor has been implicated as a mechanism for inducing sensory neuropathy in diabetic animals (Hellweg and Hartung, 1990). Developments in gene therapy approaches have allowed dorsal root ganglia neurons to increased access of nerve growth factor; this was achieved by the injection of a herpes simplex virus (HSV) vector coding for the $\beta$ subunit of nerve growth factor into the bladder to increase nerve growth factor levels in the dorsal root ganglia; there was a corresponding increase in bladder activity (Wang et al., 2005). HSV type 1 has several characteristics which make it an ideal gene transfer vector for treating diabetic cystopathy; first, it is a double strand DNA virus that may infect and persist in a latent state within sensory neurons as part of the normal life cycle of the virus (Coffin et al., 1996). Second, HSV has a natural promoter system (the latency active pormoters LAP1 and LAP2), which may be used to drive long term transgenic expression in neurons of the peripheral nervous system (Goins et al., 1999); and third, it is possible to apply strong promoters (such as the human cytomegalovirus, the immediate early gene promoter HCMV IEp), to achieve high level transient transgenic expression in the peripheral as well as in the central nervous system (Fink et al., 1996).

In addition to cystopathy, diabetic neuropathy can also affect other organs including the gastrointestinal tract. Gastrointestinal complications of diabetes (constipation, impaired rectal sensation, and/or fecal incontinence from abnormal internal anal sphincter tone) are particularly important to lower urinary tract performance (Birnbaum et al., 2003). Pressure from an over-distended bladder can reflexively inhibit parasympathetic activity, a stimulus for fecal retention and soiling. On the other hand, straining to defecate can affect pelvic floor muscles and lead to rectocele, cystocele (in women), and an increased risk of stress incontinence and incomplete bladder emptying (Manning et al., 2003; Moore et al., 2003).

It should also be mentioned that both somatic and/or autonomic neuropathy participate in vesicourethral dysfunction. An association of bladder dysfunction and autonomic neuropathy as had been detected in a group of 53 diabetic patients by using the "sympathetic skin response test" (Ueda et al., 1997). Other reports also suggest that the "tibial somatosensory evoked potential" is an easily performed test that has a good correlation with abnormal urodynamics in diabetic patients with or without lower urinary tract symptoms (Rapidi et al., 2006).

\section{ROLE OF UROTHELIUM}

The urothelium consists of at least three layers: basal, intermediate and apical, or superficial layer (umbrella cells). This barrier function of these cells is an early recognition of one of its functions. The urothelium is able to adjust itself to large variations in urine volume as the bladder fills and empties. At the cellular level, there is exocytosis and fusion of a subapical pool of discoidal shaped vesicles with the apical plasma membrane of the superficial umbrella cells to result in increases in mucosal surface area (Wang et al., 2005). The urothelium also acts as a sensor for controlling bladder function, and in this regards it releases many mediators that affects afferent nerves and so participates in a variety of abnormalities related to diabetic bladder dysfunction. Tight junctions and the presence of specialized lipid molecules and the uroplakin protein (a crystalline protein) in the superficial layer helps to support the passive barrier functions of this layer (Apodaca, 2004). The urothelium is also covered with a sulfated polysaccharide glycosaminoglycan layer that diminishes bacterial adherence and acts as a non-specific defense mechanism against infection (Parsons, 1994). Both local (infections, mechanical and chemicals trauma) and non-local insults (spinal cord injury) can interrupt the barrier function of the urothelium. As a result, toxic substances can diffuse to the underlying tissues to induce symptoms of urgency, frequency, and pain during bladder filling and voiding (Birder and de Groat, 2007). These events can potentially change the levels of chemical mediators such as NO and ATP, which are important in epithelial integrity and proper functioning (Apodaca et al., 2003). The presence of $\mathrm{P} 2 \mathrm{X}, \mathrm{P} 2 \mathrm{Y}$ receptors on the luminal surface of the bladder suggest the role for ATP as a communicating substance in bladder function (Burnstock, 2001; Birder et al., 2002a). Activation of purinergic receptors during bladder distension has signaling role throughout the bladder. For example, Wang et al. (2005) reported that increasing hydrostatic pressure stimulates the release of ATP from the urothelium, and that upon binding to $\mathrm{P} 2 \mathrm{X}$ and possibly $\mathrm{P} 2 \mathrm{Y}$ receptors on the luminal cells, activates $\mathrm{Ca}^{2+}$ and protein kinase A dependent second messenger cascades which leads to exocytosis and membrane insertion at the apical poles of these cells. In addition, Brady et al. (2004) demonstrated a potential pathophysiological role of purine expressing fibers in human subjects with neurogenic detrusor overactivity. Additional data suggests that ATP increases the currents evoked by capsaicin through activation of metabotropic $\mathrm{P} 2 \mathrm{Y}$ receptors in a protein kinase $\mathrm{C}$-dependent pathway. The large amounts of ATP released from damaged or sensitized cells in response to injury or inflammation can trigger the sensation of pain (Tominaga et al., 2001). The urothelium and bladder nerves have many receptors and ion channels in common, implying that injury or inflammation can alter the response of both urothelial cells and sensory afferents to nociceptive and other stimuli simultaneously (Yoshimura et al., 2005).

The bladder epithelium also synthesizes prostanoids such as prostaglandins F $2 \alpha$ and E2, important mediators of bladder function under both normal and pathological conditions (Pinna et al., 1994). There is an impaired endogenous prostaglandin release from epithelial preparations in type 1 diabetic rats, which may be related to for bladder abnormalities occurring during diabetes (Pinna et al., 2000). Bradykinin and ATP and bradykinin increase the release of endogenous prostaglandins from the bladder epithelium, suggesting 
the presence of both bradykinin receptors and purinergic receptors not only in the detrusor smooth muscle but also in the epithelial layer (Pinna et al., 2000). Bradykinin induced release of prostaglandin E2 has been demonstrated in human urothelial cell cultures (Zenser et al., 1988).

The prevalence of bacteriuria and urinary tract infections is much higher in diabetic women compared to healthy individuals (Stapleton, 2002). This process is initiated by the colonization of the vaginal and periurethral epithelium and then ascension to the bladder or bacteremia will occur. Type 1 fimbriated $E$. coli have a higher affinity for epithelial cells of diabetic patients - they bind to uroplakin proteins on the luminal surface of bladder and then invade the bladder wall (Geerlings et al., 2002). Internalization of the micro-organisms and formation of intracellular colonies in umbrella cells may be a pathway to chronic urinary tract infection (Schilling and Hultgren, 2002).

Nitric oxide is synthesized by a family of enzymes known as NOSs [endothelial (eNOS), inducible (iNOS), and neuronal (nNOS)]. There is activation of NOS in the urothelium, smooth muscle, striated muscle, nerves, and blood vessels of the lower urinary tract of humans and of laboratory animal models. The smooth muscle relaxing effect of $\mathrm{NO}$ on detrusor muscle has been shown in animal studies (Mumtaz et al., 2000). For example, Birder et al. (2002b) reported that the activation of $\beta$-adrenoceptors stimulates the adenylate cyclase pathway in epithelial cells of rat bladder, and this increases intracellular $\mathrm{Ca}^{2+}$ and so triggers $\mathrm{NO}$ production and release. NO may also have a regulatory effect in bladder blood supply during the voiding and filling phases (Ho et al., 2004). In addition, there may also be a protective effect of NOS inhibition with $N$-nitro-L-arginine (L-NAME) on ischemia reperfusion induced apoptosis in the rat bladder (Saito and Miyagawa, 2002). NO also plays an important role in the relaxation of the urethra and urethral sphincter (Mamas et al., 2003). Inhibitors such as L-NAME can attenuate urethral smooth relaxation while NO donors could have therapeutic roles in the treatment of sphincter spasticity and obstruction (Haab, 2000; Reitz et al., 2004). It has long been known that NO may have a role in non-adrenergic, non-cholinergic neurotransmission in the lower urinary tract, a suggestion that was strengthened by immunohistochemical evidence for NOS activity in the striated muscles of human urethral sphincters (Mamas et al., 2003). Stimulation of the parasympathetic input to the urethra elicits NO-dependent urethral smooth muscle relaxation in rats (Mumtaz et al., 2000).

Increases in NOS activity in the urothelium, smooth muscle, and intramural neurons of the bladder neck and urethra of diabetic rabbits are not accompanied by changes in intracellular cGMP (Mumtaz et al., 2000). Moreover, in spite of increased NOS activity, NO-dependent bladder outlet and urethral relaxation was impaired in diabetic individuals. These findings suggest that enhancement of NO-cGMP coupling could be an additional therapeutic option (Birder et al., 2002b).

\section{DIAGNOSIS}

\section{HISTORY, SIGNS, AND SYMPTOMS}

Both physicians and patients are equally concerned about a variety of diabetic complications such as neuropathy, retinopathy, or nephropathy, and on the other hand, bothersome bladder functions being attributed to diabetes including polyuria. Nearly $25-50 \%$ of patients do not complain of voiding problems unless specifically asked (Frimodt-Møller, 1978). Understanding the symptoms experienced by the patient is an important initial step. Since diabetic bladder dysfunction is a slowly progressing and insidious disease, patients can overlook early signs and symptoms. Ueda et al. (1997) examined 53 asymptomatic diabetic patients and found that upon careful questioning, nearly $40 \%$ expressed a voiding complaint. The classic symptoms of reduced bladder contractility are usually manifested as hesitancy, weak stream, dribbling, sense of incomplete emptying, leaking with increased abdominal pressure, and infrequent voiding (Hunter and Moore, 2003). However, more recent clinical studies show considerable diversity in the signs and symptoms of this disease. A urological study done by Starer and Libow (1990) in a sample of 23 elderly diabetic patients reported that only $17 \%$ presented with urinary retention (which is consistent with the classical definition of diabetic cystopathy), while $76 \%$ had involuntary bladder contractions presenting as urgency and/ or nocturia. These findings are important considerations when choosing therapeutic modalities for elderly diabetic patients. A detailed history of the patient's symptoms will guide management strategies, while additional information about their diabetes and glycemic control may provide information about the severity of disease. Past medical and surgical history and use of drugs that could affect the bladder function or produce functional limitation should be obtained. Since diabetic cystopathy is s a manifestation of autonomic neuropathy, screening for other signs of autonomic dysfunction particularly heart rate and orthostatic hypotension could be helpful (Hunter and Moore, 2003).

\section{WORKUP}

The history taking and physical examination of diabetic patients who have signs and symptoms of bladder dysfunction should be followed by laboratory workup tests. The rate of bacterial cystitis is higher in diabetic subjects, so urinalysis and culture with some additional biochemical tests for the assessment of diabetic control and also screening for end organ damage (such as serum glucose, glycosylated hemoglobin, urea, and creatinine) should be ordered. Other diseases and conditions that can induce or aggravate vesicourethral dysfunction should also be considered. Thus it is important to rule out neurological disorders, especially cerebrovascular accidents, or lumbar disk disorders that can also cause urinary symptoms mimicking those found in diabetes mellitus. Examination for benign prostatic hypertrophy, anal sphincter tone, saddle anesthesia, and bulbocavernosus reflex is important, while examination of females should also include a complete urogynecological examination to rule out pelvic organ prolapse such as cystocele or other forms of pelvic prolapse; an assessment of the integrity of pelvic floor muscle should be done in females. Urodynamic studies are key components of patient examination, and can include a simple cystometrogram, simultaneous pressure/flow studies, uroflow, sphincter electromyography, and evaluation of leak point pressures plus measurement of post void residue (Goldman and Appell, 1999).

A study by Lee et al. (2004) compared the voiding behavior of 194 women with type 2 diabetes with that in 162 control women, using a lower urinary tract symptoms questionnaire and uroflowmetry. They found that diabetic women had significantly higher 
nocturia scores, weaker urinary streams, reduced voided volumes, and lower maximal flow rates. Residual urine volume $(100 \mathrm{ml}$ or greater) occurred in a significantly higher proportion of diabetic subjects (13.9 vs. 1.8\% of controls). Likewise Ho et al. (2010) analyzed the urodynamic findings of 94 diabetic patients with a variety of lower urinary tract symptoms. Over active bladder was seen in $36.2 \%$ of diabetics with a higher percentage of increased bladder sensation and detrusor overactivity, lower peak flow rate, greater post void residue volume, and lower bladder voiding efficiency. On pressure flow studies, the over active bladder group had a higher percentage of bladder outlet obstruction (26.5 vs. 6.7\%). Since they had excluded women with other causes of bladder outlet obstruction such as anti-incontinence surgery or pelvic organ prolapse, it is likely that the majority of bladder outlet obstruction in this group of patients was due to functional obstruction (sometimes termed sphincter dyssynergia; Kitami, 1991). Finally, Kitami (1991) evaluated vesicourethral dysfunction in 173 diabetic patients ( 78 male, 95 female). In his study, diabetic patients showed a range of vesicourethral dysfunctions such as overactive bladder $(14.5 \%)$, low compliance bladder (11\%), and loss of detrusor external sphincter coordination $(31.7 \%)$. The study also showed a significant correlation between the extent of pyuria and ectasis of the upper urinary tract with residual urine volume and detrusor external sphincter coordination. With time and with decompensation of THE bladder, the post void residual volume increases and this can lead to long-standing chronic urinary tract infection and irreversible bladder fibrosis. Fibrotic obstruction of ureterovesical junction causes hydroureteronephrosis that is followed by renal impairment. Thus proper management of diabetic patients in the early stages of the disease is of paramount importance as this can prevent or delay many of the complications of bladder dysfunction.

\section{TREATMENT MODALITIES}

The choice of a specific treatment of diabetic cystopathy depends on the urodynamic abnormalities found. Management goals include relief of symptoms, prevention and treatment of urinary tract infections, and adequate bladder emptying. In this regard, the management strategies can be grouped into three classes: behavioral, pharmacological, and surgical.

\section{BEHAVIORAL MODALITIES}

As a first stage of treatment, non-invasive strategies should be considered. A large, randomized clinical trial study of prediabetic subjects performed by the Diabetes Prevention Program Research Groups showed that lifestyle modification is more effective than metformin in reducing the incidence of diabetes in high risk population (Knowler et al., 2002). Thus weight reduction improves urinary incontinence in obese women and should be considered an initial step for moderately obese women as part of non-surgical treatment of incontinence (Subak et al., 2002). A recent study analyzed the results of the Diabetes Prevention Program study and concluded that life style modification consisting of a 5-10\% weight reduction substantially lowered symptoms of incontinence (Brown et al., 2006). Other recommendations may include changes in diet, assessing the amount and timing of fluid intake, and bladder and pelvic muscle training.
Recent research has focused on the supplementation of diet with thiamine or cyclohexanoic long chain fatty acids. Some encouraging results show that these compounds can diminish or even prevent diabetic cystopathy (Suzuki et al., 2006; Yenilmez et al., 2006; Saito et al., 2007). Patients must be educated to minimize nocturnal polyuria, by confining most fluid intake to the morning or early afternoon, avoiding bladder irritants such as caffeinated beverages, and void before going to bed (Hunter and Moore, 2003). Alcohol is also a diuretic, so patients should expect greater urinary volumes if they consume it. Attention should also be given to maintaining regular bowel habits by increasing fiber consumption via appropriate foods or supplements, especially in constipated patients. Emphasizing better glucose control, improving blood pressure control, and encouraging cigaret-smoking cessation are also very important components in such patients (Ho et al., 2007).

Pelvic floor exercises, or Kegel exercises, are useful to strengthen the pubococcygeus muscles of the pelvic floor, which support the structures of the bladder and urethra. These exercises are helpful in stress, urge and mixed incontinence. Patients may be given some simple instructions to identify and contract appropriate muscles. One technique is to insert a finger into the vagina, or rectum (in men): then the patient is encouraged to tighten the muscles around the finger as if holding back urine. The abdominal and thigh muscles should stay relaxed. Referral to a physical therapist specializing in pelvic floor physical therapy may help patients learn the correct technique. A systematic review of 96 randomized controlled trials and 3 systematic reviews concluded that pelvic floor muscle training and bladder training resolved urinary incontinence in most women (Shamliyan et al., 2008).

Patients should be encouraged to void frequently (every 2-4 h) and to use a double voiding technique. This technique helps to prevent urinary incontinence by performing two micturitions, which will empty the bladder more effectively. In patients with a hypotonic or atonic bladder, Crede's manual compression of the lower abdomen or the Valsalva's maneuver can also be useful in facilitating micturition (Fedele, 2005). However, clean intermittent self-catheterization is the primary therapy for impaired or absent detrusor muscle activity (Ho et al., 2007). There is no evidence to support the choice of either sterile or clean techniques in patients with diabetes (Hunter and Moore, 2003). The interval between catheterizations should be designed to maintain a residual volume of less than $400 \mathrm{cc}$ and to avoid incontinence. Many patients are reluctant to use a catheter because they are uncomfortable with the anatomy, or find it painful. Patients who develop recurrent urinary tract infections are started on antimicrobial prophylaxis therapy.

\section{PHARMACOLOGICAL TREATMENTS}

Antimuscarinic agents represent the cornerstone of treatment for patients who present with an overactive bladder. These agents inhibit the binding of acetylcholine at muscarinic $\mathrm{M}_{2}$ and $\mathrm{M}_{3}$ receptors on detrusor smooth muscle cells and other structures within the bladder wall, thus, reducing the contractions of the detrusor muscle and controlling involuntary detrusor contractions without disturbing normal voiding. However, there is some uncertainty about the effectiveness of this group of drugs. A systematic review of randomized controlled trials showed that the differences between anticholinergic drugs and placebo, in terms of patient perceived 
cure or improvement, was smaller than expected from clinical experiences (Herbison et al., 2003). On the other hand, a meta-analysis of 56 randomized controlled trials found that antimuscarinics are safe and efficacious, and all of them except oxybutynin immediate release (IR) are well tolerated. The extended release (ER) form of tolterodine is the only formulation with fewer total treatment discontinuations compared with placebo (Chapple et al., 2005). Tolterodine and oxybutynin are clinically equipotent in treating detrusor overactivity in specific severity groups of patients, although the urodynamic effects are somewhat different (Giannitsas et al., 2004). A comparison between newer antimuscarinic (solifenacin, darifenacin) and the more established agents shows similar efficacy. In comparisons between IR and ER formulations, the latter showed more advantages both in terms of efficacy and safety (Novara et al., 2008). However, another randomized, double blind study suggests a superiority of solifenacin over an ER formulation of tolterodine (Chapple et al., 2007).

Trospium chloride is an anticholinergic agent with predominantly peripherally acting non-selective antimuscarinic activity. This drug has three unique pharmacokinetic properties; it is a quaternary ammonium compound, which minimizes its central nervous system penetration and therefore has fewer adverse cognitive effects. Second, it is not metabolized by the cytochrome P450 system, resulting in a reduced tendency for drug-drug interactions; and third, it is excreted in urine in the form of the active parent compound, providing for an early onset local effect. It has shown promising effects in the treatment of overactive bladder and currently is being considered as an alternative for patients who do not tolerate oxybutynin well (Biastre and Burnakis, 2009). Some studies report that trospium has superior features compared to tolterodine in terms of decreasing the frequency of micturition and incontinence episodes (Junemann and Al-Shukri, 2000).

Fesoterodine is an anticholinergic drug that functionally acts as a prodrug. It is rapidly and extensively hydrolyzed by nonspecific esterases to 5-hydroxymethyl tolterodine (5-HMT), so bypassing the CYP system [although cytochrome P450 (CYP) is involved in the subsequent inactivation of the active metabolite]. The conversion is rapid and virtually complete, such that after oral dosing only the metabolite, and not the parent compound, can be detected in patient plasma. This active metabolite is responsible for the antimuscarinic activity of fesoterodine, and is the active metabolite of tolterodine. Tolterodine is converted to 5-HMT by the CYP2D6 enzyme system. Thus, the efficacy of conversion of tolterodine to 5-HMT is can vary with the activity and expression of CYP2D6 in individual patients (Ellsworth, 2009). The efficacy and safety of fesoterodine in overactive bladder treatment appears to bet similar to that of tolterodine. The available data does not show a substantial advantage of fesoterodine over tolterodine ER in either efficacy or safety (Tzefos et al., 2009).

Propiverine hydrochloride is an agent that has combined antimuscarinic and calcium antagonistic action. Inhibition of calcium influx that underlies musculotropic spasmolysis is an important consideration in treating an overactive bladder and may result in a reduction in the frequency of micturition (Lee et al., 2010).
In general, anticholinergic drugs cause dry mouth, blurred vision, somnolence, dizziness, cognitive problems, and constipation. Close angle glaucoma is a contraindication for anticholinergic treatment. The most common side effect and reason for non-compliance is dry mouth (Chapple et al., 2005). Patients need to be monitored for retention and post void residual on follow up visits despite reports of symptomatic improvement.

Imipramine is a tricyclic antidepressant that has been extensively used in the treatment of over active bladder, and appears useful in managing diabetic autonomic dysfunction such as incontinence (Duby et al., 2004). This drug inhibits the re-uptake of noradrenaline and serotonin by adrenergic nerve endings, resulting in increased contractile effects of noradrenaline on urethral smooth muscle and enhanced detrusor muscle relaxation. In addition to blocking amine re-uptake, imipramine also has a direct smooth muscle relaxing effect that could contribute to increased storage function. Chronic administration of imipramine has shown to be clinically effective in improving functional bladder capacity by a reduction in detrusor pressure concurrent with an increased resting sphincter tonus (Hunsballe and Djurhuus, 2001). However, tricyclic antidepressants, including imipramine, can cause serious side effects (including increased dependency and some cardiovascular risks) a careful consideration should be given to the risks and benefits of this drug in the management of incontinence and over active bladder is needed.

Sadly, pharmacotherapy has a limited role in the treatment of detrusor areflexia. Attempts have been made to simulate detrusor muscle by administration of parasympathomimetic drugs. Such drugs stimulate the autonomic effector cells and postganglionic parasympathetic receptors resulting in increased intravesical pressure and decreased bladder capacity. The side effects of cholinergic agents (such as sweating, salivation, tachycardia, and flushing) limit the daily use of them. In patients with consistent residual volumes of over $100 \mathrm{~mL}$ but not exceeding $500 \mathrm{~mL}$, treatment with bethanechol (10-20 mg orally three to four times a day) may be beneficial. This drug has relatively selective actions on the urinary bladder and has also been used to facilitate reflex bladder contraction in patients with suprasacral spinal cord injury (Wein et al., 1992). If side effects occur, booster doses of bethanechol (30-60 mg orally twice weekly) have proved equally effective (Ziegler, 2001). Carbachol chloride, which has additional ganglion stimulating properties, enhances bladder motility (Wein et al., 1992).

Alpha-methyl-dopa and phenoxybenzamine have been studied as other therapeutic options. There were two reasons for trying these drugs. First, the bladder neck and posterior urethra contain a predominance of alpha adrenergic receptors. Agents that block or depress their function promote bladder neck and urethral relaxation. Second, postganglionic sympathetic fibers regulate transmission of cholinergic discharge of the pelvic parasympathetic ganglia. Blockade of this effect facilitates bladder contraction by improving the transmission at the pelvic parasympathetic ganglia. However, these agents have provided limited clinical benefits and are rarely used (Raz et al., 1977; Tammela, 1986) (Figure 1). 


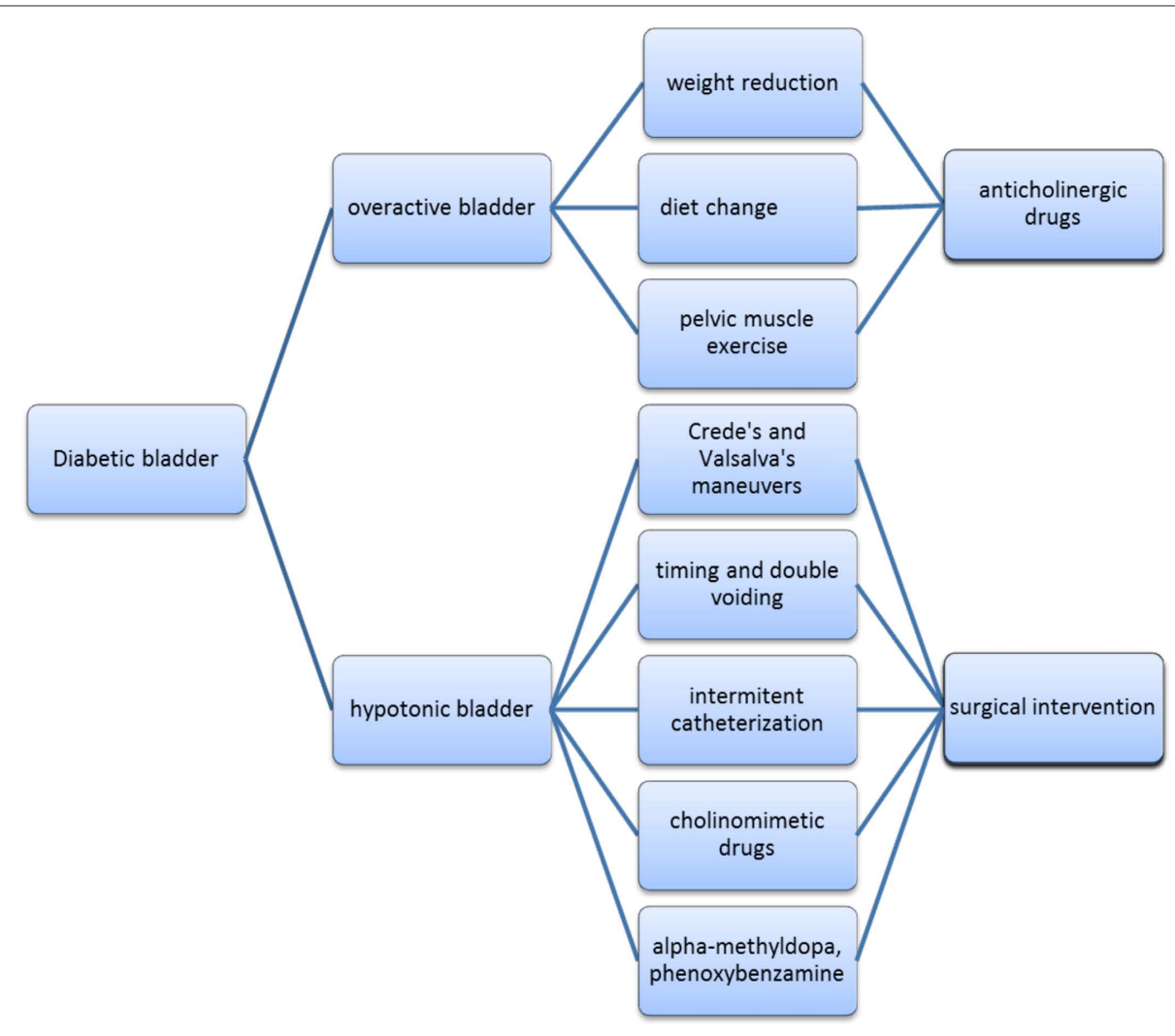

FIGURE 1 |Treatment levels for diabetic bladder.

\section{SURGICAL TREATMENTS}

Patients with the classical signs of diabetic cystopathy (impaired detrusor contractility) but who do not benefit from non-pharmacological and pharmacological interventions are candidates for surgical intervention. The aim of these procedures is to minimize the risk of urinary tract infection. Vesical neck resection, which is performed through a transurethral rout and leaves the external sphincter intact to preserve urinary continence, has been advocated by some authors (Zincke et al., 1974). The rationale for this procedure is based on resistance reduction in the presence of a hypotonic bladder. There is, however, a risk of retrograde ejaculation in men and cystourethrocele in women. In addition, the function of the external sphincter may be impaired due to diabetic neuropathy and also lead to urinary incontinence (Frimodt-Møller and Mortensen, 1980). Bladder outlet resistance may also be reduced by selective pudendal nerve block. In this procedure, a solution of $1 \%$ lidocaine is used initially to determine if micturition is improved and post voiding residual volume decreased, before a unilateral pudendal neurectomy is considered as a treatment option (Fedele, 2005).

Sacral neuromodulation (SNM) is another approved method for urinary urge incontinence, urge-frequency incontinence, and non-obstructive urinary retention refractory to non-surgical treatment. In this method a small wire lead is placed in the S3-S4 sacral foramen, which is then connected to an implantable pacemaker. Usually this method is performed in two steps; the first stage is a trial stage in which a fine wire lead is introduced into the sacral nerve foramen (S3) for a test period of 1-4 weeks. If the patient improve more than $50 \%$ based on objective and subjective evaluation, then stage two or permanent step, in which an implantable pulse generator is placed in the soft tissue of the patient's buttock (Daneshgari and Moy, 2005). In a study on diabetic patients by Daniels et al. (2010) they showed a success rate of $69.2 \%$ in urge incontinence, $85.7 \%$ of those with urgency-frequency, and $66.7 \%$ of those with urinary retention which was not different from nondiabetic cohorts. However, diabetic patients had a higher incidence of device explantation due to infection (37.5 vs. 25.5\%).

\section{SUMMARY}

Diabetic bladder dysfunction is relatively common and can have different manifestations from detrusor instability to poor bladder sensation and contraction. Diabetic neuropathy plus detrusor muscle and urothelial dysfunctions all have some role in pathophysiology. Urodynamic evaluation is the cornerstone of diagnosis and determines the actual type of bladder dysfunction and the therapeutic strategies. As non-pharmacological treatments, life style modifications such as, weight reduction, diet changes, amount, and timing of fluid intake and pelvic muscles training is recommended. For those who present with detrusor overactivity anticholinergic drugs may be an option, while pharmacotherapy has a limited role in the treatment of detrusor areflexia. Rarely, surgical intervention could render beneficial effects. Gene therapy and tissue engineering have opened new horizons with exciting promise. 


\section{REFERENCES}

Abrams, P., Andersson, K. E., Buccafusco, J. J., Chapple, C., de Groat, W. C., Fryer, A. D., Kay, G., Laties, A., Nathanson, N. M., Pasricha, P. J., and Wein, A. J. (2006). Muscarinic receptors: their distribution and function in body systems, and the implications for treating overactive bladder. Br. J. Pharmacol. 148, 565-578.

Apodaca, G. (2004). The uroepithelium: not just a passive barrier. Traffic 5, 117-128.

Apodaca, G., Kiss, S., Ruiz, W., Meyers, S., Zeidel, M., and Birder, L. (2003). Disruption of bladder epithelium barrier function after spinal cord injury. Am. J. Physiol. Renal Physiol. 284, F966-F976.

Beshay, E., and Carrier,S. (2004). Oxidative stress plays a role in diabetes-induced bladder dysfunction in a rat model. Urology 64, 1062-1067.

Biastre, K., and Burnakis, T. (2009). Trospium chloride treatment of overactive bladder. Ann. Pharmacother. 43, 283-295.

Birder, L. A., and de Groat, W. C. (2007). Mechanisms of disease: involvement of the urothelium in bladder dysfunction. Nat. Clin. Pract. Urol. 4, 46-54.

Birder, L. A., Nakamura, Y., Kiss, S., Nealen, M. L., Barrick, S., Kanai, A. J., Wang, E., Ruiz, G., De Groat, W. C., Apodaca, G., Watkins, S., and Caterina, M. J. (2002a). Altered urinary bladder function in mice lacking the vanilloid receptor TRPV1. Nat. Neurosci. 5, 856-860.

Birder, L. A., Nealen, M. L., Kiss, S., de Groat, W. C., Caterina, M. J., Wang, E., Apodaca, G., and Kanai, A. J. (2002b). Beta-adrenoceptor agonists stimulate endothelial nitric oxide synthase in rat urinary bladder urothelial cells. $J$. Neurosci. 22, 8063-8070.

Birnbaum, H., Leong, S., and Kabra, A. (2003). Lifetime medical costs for women: cardiovascular disease, diabetes, and stress urinary incontinence. Womens Health Issues 13, 204-213.

Brady, C. M., Apostolidis, A., Yiangou, Y., Baecker, P. A., Ford, A. P., Freeman, A., Jacques, T. S., Fowler, C. J., and Anand, P. (2004). P2X3-immunoreactive nerve fibres in neurogenic detrusor overactivity and the effect of intravesical resiniferatoxin. Eur. Urol. 46, 247-253.

Brown, J. S., Wessells, H., Chancellor, M. B., Howards, S. S., Stamm, W. E., Stapleton, A. E., Steers, W. D., Van Den Eeden, S. K., and McVary, K. T. (2005). Urologic complications of diabetes. Diabetes Care 28, 177-185.

Brown, J. S., Wing, R., Barrett-Connor, E., Nyberg, L. M., Kusek, J. W., Orchard, T. J., Ma, Y., Vittinghoff, E., Kanaya, A. M., and Diabetes Prevention Program
Research Group. (2006). Lifestyle intervention is associated with lower prevalence of urinary incontinence: the Diabetes Prevention Program. Diabetes Care 29, 385-390.

Burnstock, G. (2001). Purine-mediated signalling in pain and visceral perception. Trends Pharmacol. Sci. 22, 182-188.

Changolkar, A. K., Hypolite, J.A., Disanto, M., Oates, P. J., Wein, A. J., and Chacko, S. (2005). Diabetes induced decrease in detrusor smooth muscle force is associated with oxidative stress and overactivity of aldose reductase. $J$. Urol. 173, 309-313.

Chapple, C. R., Fianu-Jonsson, A., Indig, M., Khullar, V., Rosa, J., Scarpa, R. M., Mistry, A., Wright, D. M., Bolodeoku, J., and STAR Study Group. (2007). Treatment outcomes in the STAR study: a subanalysis of solifenacin $5 \mathrm{mg}$ and tolterodine ER $4 \mathrm{mg}$. Eur. Urol. 52, 1195-1203.

Chapple, C., Khullar, V., Gabriel, Z., and Dooley, J. A. (2005). The effects of antimuscarinic treatments in overactive bladder: a systematic review and meta-analysis. Eur. Urol. 48, 5-26.

Coffin, R. S., MacLean, A. R., Latchman, D. S., and Brown, S. M. (1996). Gene delivery to the central and peripheral nervous systems of mice using HSV1 ICP34.5 deletion mutant vectors. Gene Ther. 3, 886-891.

Daneshgari, F., Liu, G., Birder, L., HannaMitchell, A. T., and Chacko, S. (2009). Diabetic bladder dysfunction: current translational knowledge. J. Urol. 182, S18-S26.

Daneshgari, F., Liu, G., and Imrey, P. B. (2006). Time dependent changes in diabetic cystopathy in rats include compensated and decompensated bladder function. J. Urol. 176, 380-386.

Daneshgari, F., and Moy, M. L. (2005). Current indications for neuromodulation. Urol. Clin. North Am. 32, 37-40. Daniels, D. H., Powell, C. R., Braasch, M. R., and Kreder, K. J. (2010). Sacral neuromodulation in diabetic patients: success and complications in the treatment of voiding dysfunction. Neurourol. Urodyn. 29, 578-581.

Duby, J. J., Campbell, R. K., Setter, S. M., White, J. R., and Rasmussen, K. A. (2004). Diabetic neuropathy: an intensive review. Am. J. Health Syst. Pharm. 61, 160-173.

Ellsworth, P. (2009). Fesoterodine for the treatment of urinary incontinence and overactive bladder. Ther. Clin. Risk Manag. 5, 869-876.

Fedele, D. (2005). Therapy insight: sexual and bladder dysfunction associated with diabetes mellitus. Nat. Clin. Pract. Urol. 2, 282-290.

Fink, D. J., DeLuca, N. A., Goins, W. F., and Glorioso, J. C. (1996). Gene transfer to neurons using herpes simplex virus-based vectors. Annu. Rev. Neurosci. 19, 265-287.

Forbes, J. M., Coughlan, M. T., and Cooper, M. E. (2008). Oxidative stress as a major culprit in kidney disease in diabetes. Diabetes 57, 1446-1454.

Frimodt-Møller, C. (1978). Diabetic cystopathy. A review of the urodynamic and clinical features of neurogenic bladder dysfunction in diabetes mellitus. Dan. Med. Bull. 25, 49-60.

Frimodt-Møller, C. (1980). Diabetic cystopathy: epidemiology and related disorders. Ann. Intern. Med. 92, 318-321.

Frimodt-Møller, C., and Mortensen, S. (1980). Treatment of diabetic cystopathy. Ann. Intern. Med. 92, 327-328.

Geerlings, S. E., Meiland, R., van Lith, E. C., Brouwer, E. C., Gaastra, W., and Hoepelman, A. I. (2002). Adherence of type 1-fimbriated Escherichia coli to uroepithelial cells: more in diabetic women than in control subjects. Diabetes Care 25, 1405-1409.

Giannitsas, K., Perimenis, P. Athanasopoulos, A., Gyftopoulos, K., Nikiforidis, G., and Barbalias, G. (2004). Comparison of the efficacy of tolterodine and oxybutynin in different urodynamic severity grades of idiopathic detrusor overactivity. Eur. Urol. 46, 776-782.

Goins, W. F., Lee, K. A., Cavalcoli, J. D., O’Malley, M. E., DeKosky, S. T., Fink, D. J., and Glorioso, J. C. (1999). Herpes simplex virus type 1 vector-mediated expression of nerve growth factor protects dorsal root ganglion neurons from peroxide toxicity. J. Virol. 73, 519-532.

Goldman, H. B., and Appell, R. A. (1999). Voiding dysfunction in women with diabetes mellitus. Int. Urogynecol. J. Pelvic Floor Dysfunct. 10, 130-133.

Haab, F. (2000). Discussion: nitric oxide and bladder overactivity. Urology 55 , 58-59.

Hegde, S. S. (2006). Muscarinic receptors in the bladder: from basic research to therapeutics. Br. J. Pharmacol. 147, S80-S87.

Hellweg, R., and Hartung, H. D. (1990) Endogenous levels of nerve growth factor (NGF) are altered in experimental diabetes mellitus: a possible role for NGF in the pathogenesis of diabetic neuropathy. J. Neurosci. Res. 26, 258-267.

Herbison, P., Hay-Smith, J., Ellis, G., and Moore, K. (2003). Effectiveness of anticholinergic drugs compared with placebo in the treatment of overactive bladder: systematic review. BMJ 326, 841-844.

Hill, S. R., Fayyad, A. M., and Jones, G. R. (2008). Diabetes mellitus and female lower urinary tract symptoms: a review. Neurourol. Urodyn. 27, 362-367.

Ho, C. H., Tai, H. C., and Yu, H. J. (2010). Urodynamic findings in female diabetic patients with and without overactive bladder symptoms. Neurourol. Urodyn. 29, 424-427.

Ho, M. H., Bhatia, N. N., and Khorram, O. (2004). Physiologic role of nitric oxide and nitric oxide synthase in female lower urinary tract. Curr. Opin. Obstet. Gynecol. 16, 423-429.

Ho, M.H., Yip, S., and Bhatia, N. N. (2007). Lower urinary tract dysfunctions in women with diabetes mellitus. Curr. Opin. Obstet. Gynecol. 19, 469-473.

Hunsballe,J.M., and Djurhuus, J.C.(2001). Clinical options for imipramine in the management of urinary incontinence. Urol. Res. 29, 118-125.

Hunter, K. F., and Moore, K. N. (2003). Diabetes-associated bladder dysfunction in the older adult (CE). Geriatr. Nurs. 24, 138-145.

Junemann, K. P., and Al-Shukri, S. (2000). Efficacy and tolerability of trospium chloride and tolterodine in 234 patients with urge syndrome: a double blind, placebo controlled multicenter clinical trial. Neurourol. Urodyn. 19, 488-493.

Kaplan, S. A., Te, A. E., and Blaivas, J. G. (1995). Urodynamic findings in patients with diabetic cystopathy. $J$. Urol. 153, 342-344.

Kebapci, N., Yenilmez, A., Efe, B., Entok, E., and Demirustu, C. (2007). Bladder dysfunction in type 2 diabetic patients. Neurourol. Urodyn. 26, 814-819.

Kitami, K. (1991). Vesicourethral dysfunction of diabetic patients. Nippon Hinyokika Gakkai Zasshi 82, 1074-1083.

Knowler, W. C., Barrett-Connor, E., Fowler, S. E., Hamman, R. F., Lachin, J. M., Walker, E. A., Nathan, D. M., and Diabetes Prevention Program Research Group. (2002). Reduction in the incidence of type 2 diabetes with lifestyle intervention or metformin. $N$. Engl. J. Med. 346, 393-403.

Kubota, Y., Nakahara, T., Mitani, A., Maruko, T., Sakamoto, K., and Ishii, K. (2003). Augmentation of rat urinary bladder relaxation mediated by betal-adrenoceptors in experimental diabetes. Eur. J. Pharmacol. 467, 191-195.

Lee, K. S., Lee, H. W., Choo, M. S., Paick, J. S., Lee, J. G., Seo, J. T., Lee, J. Z., Lee, Y. S., Yoon, H., Park, C. H., Na, Y. G., Jeong, Y. B., Lee, J. B., and Park, W. H. (2010). Urinary urgency outcomes after propiverine treatment for an overactive bladder: the 'Propiverine study on overactive bladder including urgency data'. BJU Int. 105, 1565-1570.

Lee, W. C., Wu, H. P., Tai, T. Y., Liu, S. P., Chen, J., and Yu, H. J. (2004). Effects of 
diabetes on female voiding behavior. J. Urol. 172, 989-992.

Levi-Montalcini, R. (1987). The nerve growth factor 35 years later. Science 237, 1154-1162.

Mamas, M.A., Reynard, J.M., and Brading, A. F. (2003). Nitric oxide and the lower urinary tract: current concepts, future prospects. Urology 61, 1079-1085.

Manning, J., Korda, A., Benness, C., and Solomon, M. (2003). The association of obstructive defecation, lower urinary tract dysfunction and the benign joint hypermobility syndrome: a casecontrol study. Int. Urogynecol. J. Pelvic Floor Dysfunct. 14, 128-132.

Michel, M. C., de la Rosette, J. J., Piro, M., and Goepel, M. (2004). Does concomitant stress incontinence alter the efficacy of tolterodine in patients with overactive bladder? J. Urol. 172, 601-604.

Michel, M. C., and Vrydag, W. (2006). Alpha1-, alpha2- and beta-adrenoceptors in the urinary bladder, urethra and prostate. Br. J. Pharmacol. 147, S88-S119.

Moore, K. N., Saltmarche, B., and Query, A. (2003). Urinary incontinence. Non-surgical management by family physicians. Can. Fam. Physician 49, 602-610.

Mumtaz, F. H., Khan, M. A., Thompson, C. S., Morgan, R. J., and Mikhailidis, D. P. (2000). Nitric oxide in the lower urinary tract: physiological and pathological implications. BJU Int. 85, 567-578.

Novara, G., Galfano, A., Secco, S., D’Elia, C., Cavalleri, S., Ficarra, V., and Artibani, W. (2008). A systematic review and meta-analysis of randomized controlled trials with antimuscarinic drugs for overactive bladder. Eur. Urol. 54, 740-763.

Parsons, C. L. (1994). The therapeutic role of sulfated polysaccharides in the urinary bladder. Urol. Clin. North Am. 21, 93-100.

Peters, S. L., Schmidt, M., and Michel, M. C. (2006). Rho kinase: a target for treating urinary bladder dysfunction? Trends Pharmacol. Sci. 27, 492-497.

Pinna, C., Bolego, C., and Puglisi, L. (1994). Effects of substance $P$ and capsaicin on urinary bladder of diabetic rat and the role of the epithelium. Eur. J. Pharmacol. 271, 151-158.

Pinna, C., Zanardo, R., and Puglisi, L. (2000). Prostaglandin-release impairment in the bladder epithelium of streptozotocin-induced diabetic rats. Eur. J. Pharmacol. 388, 267-273.

Rapidi, C. A., Karandreas, N., Katsifotis, C., Benroubi, M., Petropoulou, K., and Theodorou, C. (2006). A combined urodynamic and electrophysi- ological study of diabetic cystopathy. Neurourol. Urodyn. 25, 32-38.

Raz, S., Kaufman, J. J., Ellison, G. W., and Mayers, L. W. (1977). Methyldopa in treatment of neurogenic bladder disorders. Urology 9, 188-190.

Reitz, A., Bretscher, S., Knapp, P. A., Müntener, M., Wefer, B., and Schurch, B. (2004). The effect of nitric oxide on the resting tone and the contractile behaviour of the external urethral sphincter: a functional urodynamic study in healthy humans. Eur. Urol. 45, 367-373.

Saito, M., Kinoshita, Y., Satoh, I., Shinbori, C., Suzuki, H., Yamada, M., Watanabe, T., and Satoh, K. (2007). Ability of cyclohexenonic long-chain fatty alcohol to reverse diabetes-induced cystopathy in the rat. Eur. Urol. 51, 479-487.

Saito, M., and Miyagawa, I. (2002).N(G)nitro-L-arginine methylester, a nitric oxide synthase inhibitor, diminishes apoptosis induced by ischemia-reperfusion in the rat bladder. Neurourol. Urodyn. 21, 566-571.

Saito, M., Nakamura, I., and Miyagawa, I. (1997). Autoradiographic localization of muscarinic receptors in diabetic rat bladder. Nippon Hinyokika Gakkai Zasshi 88, 858-867.

Satriano, J. (2007). Kidney growth, hypertrophy and the unifying mechanism of diabetic complications. Amino Acids 33, 331-339.

Schilling, J. D., and Hultgren, S. J. (2002). Recent advances into the pathogenesis of recurrent urinary tract infections: the bladder as a reservoir for uropathogenic Escherichia coli. Int. J. Antimicrob. Agents 19, 457-460.

Shamliyan, T. A., Kane, R. L., Wyman, J., and Wilt, T. J. (2008). Systematic review: randomized, controlled trials of nonsurgical treatments for urinary incontinence in women. Ann. Intern. Med. 148, 459-473.

Smith, D. B. (2006). Urinary incontinence and diabetes: a review.J. Wound Ostomy Continence Nurs. 33, 619-623.

Stapleton, A. (2002). Urinary tract infections in patients with diabetes. Am. J. Med. 113(Suppl. 1A), 80S-84S.

Starer,P., and Libow,L. (1990). Cystometric evaluation of bladder dysfunction in elderly diabetic patients. Arch. Intern. Med. 150, 810-813.

Steers, W. D., and Tuttle, J. B. (2006). Mechanisms of disease: the role of nerve growth factor in the pathophysiology of bladder disorders. Nat. Clin. Pract. Urol. 2, 101-110.

Subak, L. L., Johnson, C., Whitcomb, E., Boban, D., Saxton, J., and Brown, J. S. (2002). Does weight loss improve incontinence in moderately obese women? Int. Urogynecol. J. Pelvic Floor Dysfunct. 13, 40-43.
Suzuki, H., Saito, M., Kinoshita, Y., Satoh, I., Kono, T., ShinBori, C., Anastasios, S., Yamada, M., and Satoh, K. (2006). Preventive effects of cyclohexenonic long-chain fatty alcohol on diabetic cystopathy in the rat. Can. J. Physiol. Pharmacol. 84, 195-201.

Tammela, T. (1986). Prevention of prolonged voiding problems after unexpected postoperative urinary retention: comparison of phenoxybenzamine and carbachol. J. Urol. 136, 1254-1257.

Tammela, T. L., Briscoe, J. A., Levin, R. M., and Longhurst, P. A. (1994). Factors underlying the increased sensitivity to field stimulation of urinary bladder strips from streptozotocin-induced diabetic rats. Br. J. Pharmacol. 113 195-203.

Thoenen, H., and Barde, Y. A. (1980). Physiology of nerve growth factor. Physiol. Rev. 60, 1284-1335.

Tominaga, M., Wada, M., and Masu, M. (2001). Potentiation of capsaicin receptor activity by metabotropic ATP receptors as a possible mechanism for ATP-evoked pain and hyperalgesia. Proc. Natl. Acad. Sci. U.S.A. 98, 6951-6956.

Tong, Y. C., and Cheng, J. T. (2007). Aldose reductase inhibitor ONO2235 restores the alterations of bladder nerve growth factor and neurotrophin receptor p75 genetic expression in streptozotocin induced diabetic rats. J. Urol. 178, 2203-2207.

Tong, Y. C., Chin, W. T., and Cheng, J. T. (1999). Alterations in urinary bladder M2-muscarinic receptor protein and mRNA in 2-week streptozotocininduced diabetic rats. Neurosci. Lett. 277, 173-176.

Tzefos, M., Dolder, C., and Olin, J. L. (2009). Fesoterodine for the treatment of overactive bladder. Ann. Pharmacother. 43, 1992-2000.

Ueda, T., Yoshimura, N., and Yoshida, O. (1997). Diabetic cystopathy: relationship to autonomic neuropathy detected by sympathetic skin response. J. Urol. 157, 580-584.

Van Poppel, H., Stessens, R., Van Damme, B., Carton, H., and Baert, L. (1998). Diabetic cystopathy: neuropathological examination of urinary bladder biopsies. Eur. Urol. 15, 128-131.

Wakabayashi, Y., Maeda, T., and Kwok, Y. N. (1996). Increase of p75 immunoreactivity in rat urinary bladder following inflammation. Neuroreport 7 , 1141-1144.

Wakabayashi, Y., Tomoyoshi, T., Tooyama, I., Kitahama, K., Kim, S. U., and Maeda, T. (1995). Low-affinity nerve growth factor receptor immunoreactivity in the human urinary bladder. Neurosci. Lett. 186, 9-12.

Wang, E. C., Lee, J. M., Ruiz, W. G., Balestreire, E. M., von Bodungen, M.,
Barrick, S., Cockayne, D. A., Birder, L. A., and Apodaca, G. (2005). ATP and purinergic receptor-dependent membrane traffic in bladder umbrella cells. J. Clin. Invest. 115, 2412-2422.

Waring, J. V., and Wendt, I. R. (2000). Effects of streptozotocin-induced diabetes mellitus on intracellular calcium and contraction of longitudinal smooth muscle from rat urinary bladder. J. Urol. 163, 323-330.

Wein, A. J., Van Arsdalen, K., and Levin, R. M. (1992). "Pharmacologic therapy," in Clinical Neuro-Urology, eds R. J. Krane and M. B. Siroky (Boston: Little Brown and Company), 523-557.

Yenilmez, A., Ozçifçi, M., Aydin, Y., Turgut, M., Uzuner, K., and Erkul, A. (2006). Protective effect of high-dose thiamine (B1) on rat detrusor contractility in streptozotocin-induced diabetes mellitus. Acta Diabetol. 43, 103-108.

Yoshimura, N., Chancellor, M. B., Andersson, K. E., and Christ, G. J. (2005). Recent advances in understanding the biology of diabetes-associated bladder complications and novel therapy. BJU Int. 95, 733-738.

Zenser, T. V., Thomasson, D. L., and Davis, B. B. (1988). Characteristics of bradykinin and TPA increases in the PGE2 levels of human urothelial cells. Carcinogenesis 9, 1173-1177.

Ziegler, D. (2001). Diagnosis and treatment of diabetic autonomic neuropathy. Curr. Diab. Rep. 1, 216-227.

Zincke, H., Campbell, J. T., Palumbo, P. J., and Furlow, W. L. (1974). Neurogenic vesical dysfunction in diabetes mellitus: another look at vesical neck resection. J. Urol. 111, 488-490.

Conflict of Interest Statement: The authors declare that the research was conducted in the absence of any commercial or financial relationships that could be construed as a potential conflict of interest.

Received: 22 September 2010; paper pending published: 29 September 2010; accepted: 29 October 2010; published online: 16 November 2010.

Citation: Golbidi S and Laher I (2010) Bladder dysfunction in diabetes mellitus. Front. Pharmacol. 1:136. doi: 10.3389/ fphar.2010.00136

This article was submitted to Frontiers in Cardiovascular and Smooth Muscle Pharmacology, a specialty of Frontiers in Pharmacology.

Copyright $\odot 2010$ Golbidiand Laher. This is an open-access article subject to an exclusive license agreement between the authors and the Frontiers Research Foundation, which permits unrestricted use, distribution, and reproduction in any medium, provided the original authors and source are credited. 